\title{
CALIPSO Retrieval of Instantaneous Faint Aerosols
}

\author{
Feiyue Mao ${ }^{1,2}$, Ruixing $\mathrm{Shi}^{1}$, Daniel Rosenfeld ${ }^{3}$, Zengxin $\mathrm{Pan}^{3, *}$, Lin Zang ${ }^{4}$, Yannian Zhu ${ }^{5,6}, \mathrm{Xin} \mathrm{Lu}^{2}$
}

${ }^{1}$ School of Remote Sensing and Information Engineering, Wuhan University, Wuhan 430079, China

${ }^{2}$ State Key Laboratory of Information Engineering in Surveying, Mapping, and Remote Sensing, Wuhan University, Wuhan

5430079 , China

${ }^{3}$ Institute of Earth Sciences, The Hebrew University of Jerusalem, Jerusalem 91904, Israel

${ }^{4}$ Chinese Antarctic Centre of Surveying and Mapping, Wuhan University, Wuhan 430079, China

${ }^{5}$ School of Atmospheric Sciences, Nanjing University, Nanjing 210023, China

${ }^{6}$ Joint International Research Laboratory of Atmospheric and Earth System Sciences \& Institute for Climate and Global

Change Research, Nanjing University, Nanjing 210023, China

Correspondence to: Zengxin Pan (pzx@whu.edu.cn)

\begin{abstract}
Aerosols significantly affect the Earth-atmosphere energy balance and climate change by acting as cloud condensation nuclei. Particularly, the susceptibility of clouds to aerosols is more pronounced when the aerosols are faint. However, previous methodologies generally miss these faint aerosols and their climate effect based on instantaneous observations because they are too optically thin to be detected. Here, we focus on retrieving faint aerosol extinction based on instantaneous observations from the Cloud-Aerosol Lidar and Infrared Pathfinder Satellite Observations (CALIPSO). Results show a good agreement between faint aerosol extinction retrieval of CALIPSO and Stratospheric Aerosol and Gas Experiment III on the International Space Station (SAGE III-ISS) product over June 2017 to 2019 during nighttime, with correlation coefficients (R) and root mean square error (RMSE) of 0.58 in logarithmic scale and 0.0008 , respectively. The lower bound of retrieved aerosol extinction extended to $0.0001 \mathrm{~km}^{-1}$, much lower than the CALIPSO Level 2 Extinction product $\left(0.01 \mathrm{~km}^{-1}\right)$. The CALIPSO retrieval during daytime has a positive bias and low agreement with SAGE III-ISS with $\mathrm{R}$ and RMSE of 0.16 and 0.0034 , respectively, due to the low signal-to-noise ratio caused by sunlight. Additionally, the retrieval at $20 \mathrm{~km}$ resolution successfully capture the enhanced faint aerosol from Siberian fires in 2019 instantaneously, which are also shown by CALIPSO monthly-averaged aerosol product at much lower temporal-spatial resolution. It indicates a significant potential for improving the quantification of aerosol impacts on climate change through retrieving instantaneous faint aerosol.
\end{abstract}

\section{Introduction}

Aerosols significantly affect the Earth-atmosphere system through direct and indirect climate radiative forcing (Boucher et al., 2013). Increased aerosol not only perturbs atmospheric radiative balance by directly interacting with solar radiation

30 (direct effect), but also affects the cloud properties and precipitation by acting as cloud condensation nuclei and ice forming particles (indirect effect) (Dipu et al., 2013; Rosenfeld et al., 2014). Aerosols represent a major uncertainty in global climate change with a low scientific understanding (Schwartz and Andreae, 1996;Lee et al., 2016; Watson - Parris et al., 2020). The 
Cloud-Aerosol Lidar and Infrared Pathfinder Satellite Observation (CALIPSO) can detect the vertical properties of aerosols and clouds globally beyond the limitation of passive observation (Winker et al., 2010), providing unprecedented opportunities to advance the understanding of three-dimensional aerosol distribution characteristics and its global climate forcing (Adams et al., 2012;Lu et al., 2018;Song et al., 2021;Winker et al., 2013).

Aerosols are mostly concentrated in the planetary boundary layer, which forms optically thick aerosol layers and can usually be detected by CALIPSO ( $\mathrm{Li}$ et al., 2017;Kim et al., 2021). Additionally, the persistent faint aerosol in the troposphere and stratosphere, including undetected tenuous aerosol layer and background aerosol, has long been considered to have an important effect on the Earth's climate (Turco et al., 1980;Deshler, 2008; Thorsen and Fu, 2015). However, these faint aerosols are too optically thin to be detected from space, as reported that the low bound of detected aerosol optical depth (AOD) of CALIPSO Level 2 product is 0.05 (Winker et al., 2013), with a minimum detection extinction of about $0.01 \mathrm{~km}^{-1}$ as shown by Watson $\square$ Parris et al. (2018). It is noted that the AODs of faint aerosols undetected by CALIPSO can reach 0.03 0.05 , which account for approximately $20 \%$ of the total AOD and are very important for climatology (Toth et al., 45 2018; Smirnov et al., 2011;Levy et al., 2013). Previous studies generally characterize aerosol and its radiative forcing based on the observed aerosol layers, which are mostly contributed by near-surface aerosol, but Thorsen and Fu (2015) point out that CALIOP may have underestimated the magnitude of the aerosol direct radiative effect by $30 \%-50 \%$ due to its low sensitivity to tenuous aerosol layers. Additionally, aerosol significantly affects cloud formation by acting as cloud condensation nuclei. However, clouds interact directly with ambient faint aerosol instead of the near-surface aerosol,

50 especially for ice clouds (Rosenfeld et al., 2014). Thus, an improper aerosol proxy (such as AOD) will cause large uncertainty in quantifying the climate effect of aerosol.

A few studies focus on retrieving faint aerosols that CALIPSO did not detect (Kar et al., 2019;Kim et al., 2017). Kim et al. (2017) try to calculate the integrated AOD of faint aerosol undetected by CALIPSO through constraining of MODIS AOD. However, the vertical distribution of the faint aerosol was rarely discussed and verified. Recently, the CALIPSO Level 3

55 Stratospheric Aerosol Profile product was released, which well agrees with Stratospheric Aerosol and Gas Experiment III on the International Space Station (SAGE III-ISS). However, the Level 3 products have very low temporal-spatial resolution (1 month, $5^{\circ} \times 20^{\circ}$ in latitude and longitude) (Kar et al., 2019), which is insufficient to characterize the distribution and effects of faint aerosols accurately (Ma et al., 2015). Furthermore, many studies suggest that CALIPSO may potentially obtain more information on faint aerosols with appropriate data processing (Thomason et al., 2007; Vernier et al., 2009;Kar et al., 2019).

60 Thus, this study makes great efforts to retrieve faint aerosol using CALIPSO instantaneous observations.

In this study, we retrieve the instantaneous extinction coefficients of faint aerosols (both tropospheric and stratospheric), which are composed of background aerosols and undetected aerosol layers by CALIPSO feature detection $(\mathrm{AOD}<0.05)$ based on the single-track CALIPSO Level 1 data. The reliability of retrieval results is further verified by comparing them with the SAGE III-ISS aerosol extinction products. Additionally, the significance of the high temporal-spatial resolution aerosol information is also illustrated by comparison with the CALIPSO Level 3 Stratospheric Aerosol Profile product. 


\section{Data and methodology}

\subsection{CALIPSO data}

The CALIPSO mission brought new technology for retrieving aerosol profiles from space in April 2006, with a dualwavelength backscattering lidar as the primary payload (Winker et al., 2010). The CALIPSO lidar is highly sensitive to cloud/aerosol layers with a lower bound of optical depth at 0.05 (minimum detected extinction of 0.01 to $0.02 \mathrm{~km}^{-1}$ ) (Watson - Parris et al., 2018;Toth et al., 2018). CALIPSO can further distinguish the detected feature layers as aerosol or cloud layers with a high degree of confidence (>90\%) (Liu et al., 2019; Winker et al., 2013; Young et al., 2018). This study uses CALIPSO Level 1B and Level 2 VFM products for the faint aerosol extinction coefficient retrieval from June 2017 to August 2019, as shown in Table 1. Additionally, the CALIPSO Level 3 monthly-averaged Stratospheric Aerosol Profile

75 product with a resolution of $5^{\circ} \times 20^{\circ}$ in latitude and longitude will be used to compare with the retrieved extinction of faint aerosol.

\subsection{SAGE III-ISS data}

The Stratospheric Aerosol and Gas Experiment (SAGE) was developed to obtain vertical profiles of aerosols optical properties since 1984, which could detect the extinction of faint aerosol at the upper troposphere and the stratosphere

80 (Mauldin III et al., 1985;Damadeo et al., 2013). SAGE III conducts solar and lunar occultation measurements globally while orbiting the Earth on the International Space Station (ISS). The vertical profile of stratospheric aerosols is observed by the rays passing through the atmosphere during sunrise/moonrise and sunset/moonset events (Cisewski et al., 2014;Thomason et al., 2010). Previous studies have shown that the uncertainty in the aerosol extinction coefficient of SAGE III-ISS in the stratosphere (15-25 km) is within 10\% (Thomason et al., 2010). The aerosol extinction of the SAGE III-ISS product with a

85 vertical resolution of $0.5 \mathrm{~km}$ at $521 \mathrm{~nm}$ channel, which is closest to the CALIPSO $532 \mathrm{~nm}$ channel, is used for comparison and validation in this study. Because of the absence of aerosol extinction information in the SAGE III-ISS lunar occultation product, only SAGE III-ISS solar occultation product was used in this study, as shown in Table 1.

Table 1. Data used in the study with their sources and parameters.

\begin{tabular}{|c|c|c|}
\hline Source & Product & Parameter \\
\hline \multirow{3}{*}{ CALIPSO } & Level 1B Profile, Version 4.10 & $\begin{array}{l}\text { The total attenuated backscatter at } 532 \mathrm{~nm} \text {, } \\
\text { tropopause height, molecular number density, ozone } \\
\text { number density }\end{array}$ \\
\hline & Level 2 Vertical Feature Mask, Version 4.20 & Feature classification flag of aerosol and cloud \\
\hline & $\begin{array}{l}\text { Level } 3 \text { Stratospheric Aerosol Profile Monthly } \\
\text { Product }\end{array}$ & Aerosol extinction coefficient with background mode \\
\hline \multirow{2}{*}{$\begin{array}{l}\text { SAGE III- } \\
\text { ISS }\end{array}$} & \multirow{2}{*}{$\begin{array}{l}\text { Level } 2 \text { Solar Event Species Profiles, V051, } 0.5 \mathrm{~km} \\
\text { vertical interval }\end{array}$} & Aerosol extinction coefficient \\
\hline & & Aerosol extinction uncertainty \\
\hline
\end{tabular}




\subsection{Retrieving instantaneous faint aerosol extinction by CALIPSO}

90 In this study, the faint aerosol extinction coefficient is retrieved similarly to Kar et al. (2019) and Kim et al. (2017), but with a higher temporal-spatial resolution (single-track and horizontal $20 \mathrm{~km}$ ), as shown in Figure 1. To improve the signal-tonoise ratio (SNR) of the total attenuated backscatter (TAB) data, we performed the following pre-processing steps:

(a) The clouds and aerosols detected by CALIPSO VFM and the data below them is removed, as did by the CALIPSO level 3 Stratospheric Aerosol Product (Kar et al., 2019);

95 (b) The TAB is averaged at a vertical resolution of $300 \mathrm{~m}$ and followed by a vertical moving filtering (with a 5-point window) for each profile to restrict noise at $333 \mathrm{~m}$ horizontal resolution.

(c) Finally, the 300-m vertical averaged TAB profiles are averaged to $20 \mathrm{~km}$ resolution horizontally for the retrieval of faint aerosol extinction;

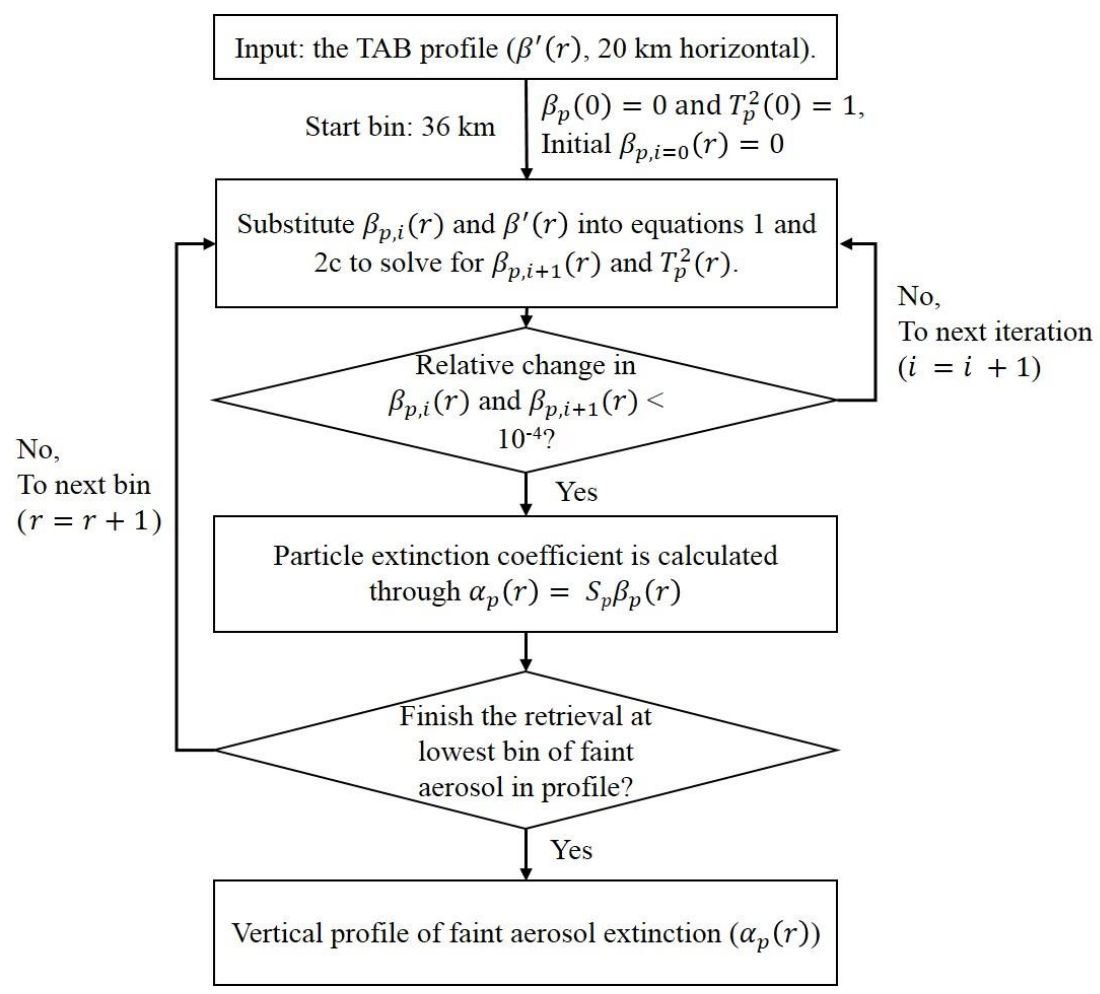

100 Figure 1: Overall algorithm flow for faint aerosol retrieval. In the figure, $\beta^{\prime}(r), \beta_{p}(r), \alpha_{p}(r)$ and $T_{P}^{2}(r)$ represent total attenuated backscatter, particulate backscatter coefficient, particulate extinction and particulate two-way transmittances, respectively. The $r$ represents the height and $i$ represents the number of iterations. The particle particulate multiple scattering factor $\left(\eta_{p}\right)$ is set to 1 , and the lidar ratio $\left(S_{p}\right)$ is set to $50 \mathrm{sr}$ and $28.75 \mathrm{sr}$ in the stratosphere and troposphere, respectively. Meanwhile, the start bin at 36 km is considered aerosol-free $\left(\beta_{p}(0)=1, T_{p}^{2}(0)=1\right.$ ) (Kar et al., 2019).

105 The SNR can be calculated according to $S N R=\mu / \sigma$ based on the TAB with $20 \mathrm{~km}$ horizontal resolution, where $\mu$ and $\sigma$ are the mean and the standard deviation of the signal, respectively (Kim et al., 2017). Based on the pre-processed TAB (i.e., 
$\beta^{\prime}(r)$ ), the particulate backscatter coefficient (i.e., $\beta_{p}(r)$ ) is solved by iterating Eqs. (1) and (2c) in the following equations.

$\beta_{p}(r)=\frac{\beta^{\prime}(r)}{T_{m}^{2}(r) T_{o_{3}}^{2}(r) T_{p}^{2}(r)}-\beta_{m}(r)$,

$110 T_{m}^{2}(r)=\exp \left(-2 \int_{0}^{r} \alpha_{m}\left(r^{\prime}\right) d r^{\prime}\right)$,

$T_{o_{3}}^{2}(r)=\exp \left(-2 \int_{0}^{r} \alpha_{o_{3}}\left(r^{\prime}\right) d r^{\prime}\right)$,

$T_{p}^{2}(r)=\exp \left(-2 \eta_{p} S_{p} \int_{0}^{r} \beta_{p}\left(r^{\prime}\right) d r^{\prime}\right)$,

$\alpha_{p}(r)=S_{p}(r) \beta_{p}(r)$,

where, $T_{m}^{2}(r), T_{o_{3}}^{2}(r)$ and $T_{p}^{2}(r)$ represent the molecular, ozone, and particulate two-way transmittances, respectively. The

molecular backscatter coefficients $\left(\beta_{m}(r)\right)$, molecular and ozone two-way transmittances $\left(T_{m}^{2}(r)\right.$ and $\left.T_{o_{3}}^{2}(r)\right)$ can be calculated from the molecular number density and ozone number density provided by CALIPSO Level 1B product (Kar et al., 2019). There are several basic settings in the retrieval algorithm. The multiple scattering coefficient $\left(\eta_{p}\right)$ for all species of faint aerosol particles is considered to be 1, as the retrieving for the CALIPSO Level 2 product (Young et al., 2018). The lidar ratio was set to $50 \mathrm{sr}$, which is a typical value used in the stratosphere (Khaykin et al., 2017;Kremser et al., 2016), while

120 it is set to $28.75 \mathrm{sr}$ in the troposphere refers to the estimate by Kim et al. (2017). Meanwhile, the bin at $36 \mathrm{~km}$ is considered aerosol-free $\left(\beta_{p}(0)=0, T_{p}^{2}(0)=1\right)$.

\subsection{Methodology of validation}

Since only daytime data from SAGE III-ISS are available, the CALIPSO orbits are spatially and temporally matched to the nearest SAGE III-ISS observations on the same day by ignoring the diurnal variation of faint aerosols in SAGE III-ISS data. Due to the low horizontal resolution $(\sim 300 \mathrm{~km})$ of the SAGE III-ISS occultation observations, we matched CALIPSO and SAGE within a $2^{\circ} \times 1^{\circ}$ (longitude $\times$ latitude) grid centred on the SAGE III-ISS observations (Adams et al., 2013). CALIPSO sometimes has very little data within the matched grid. We only retain the match where the CALIPSO orbit exceeds $0.75^{\circ}$ latitude (or four 20-km CALIPSO profiles) in the grid (Figure 2a). Due to the effects of an elevated frequency of low energy laser shots of CALIOP within South Atlantic Anomaly (SAA), the data over SAA (black rectangle in Figure 2b) is removed,

130 which accounted for 5\% of all matched profiles. Therefore, 1142 and 1087 profiles are successfully matched for CALIPSO nighttime and daytime data, respectively, from June 2017 to August 2019 (Figure 2b). The SAGE III-ISS $521 \mathrm{~nm}$ aerosol extinction products were used to verify the faint aerosol extinction we retrieved. Furthermore, we exclude SAGE bins with extinction uncertainty larger than $10 \%$ for the matched profiles. 

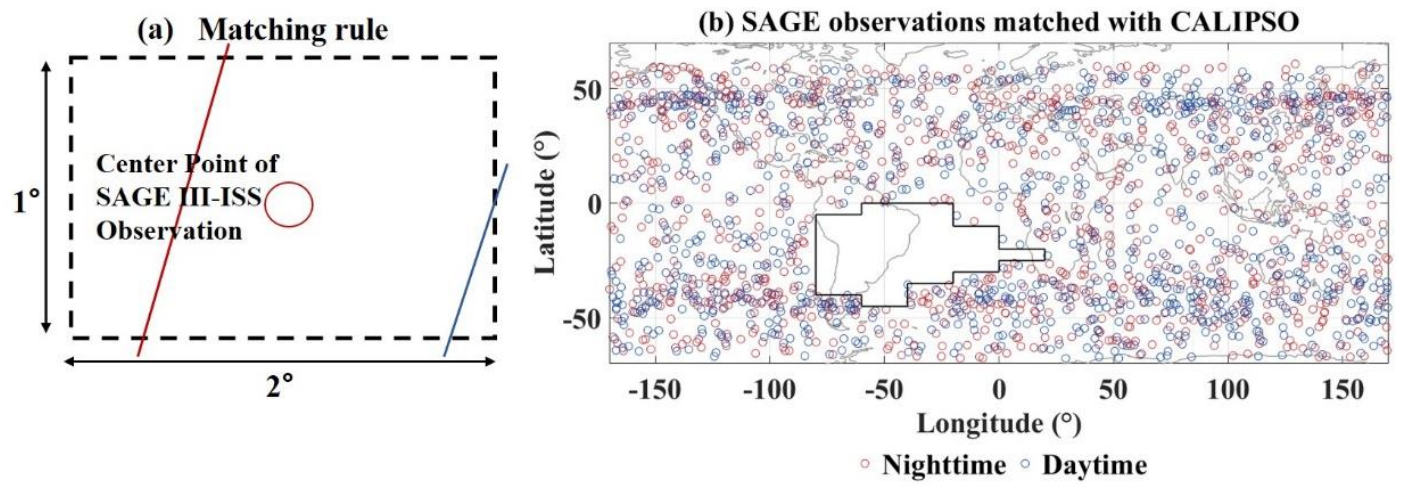

135 Figure 2. (a) Schematic diagram of the CALIPSO match to SAGE III-ISS. The red circle represents center point of SAGE III-ISS observations. The red and blue lines represent the successful and failed (CALIPSO track is less than $0.75^{\circ}$ in grid) cases, respectively. (b) Global distribution of matched SAGE III-ISS observations with CALIPSO nighttime data (1142 red circles) and daytime data (1087 blue circles), respectively, from June 2017 to August 2019. The area in the black line represents the South Atlantic Anomaly where CALIOP is experiencing an elevated frequency of low-energy laser shots.

\section{$140 \quad 3$ Results and analysis}

\subsection{Faint aerosols in wildfire cases}

Figure 3 shows a case with the retrieved faint aerosol combined with CALIPSO detected aerosol from wildfires in Australia that burned for several months. The smoke and dust transmission trajectory generated by the wildfires in Australia in August 2019 can be seen in the red dash boxed area of the Terra MODIS true-color image (Figure 3a). In the scene of aerosol

145 extinction coefficient (Figure 3c), CALIPSO Level 2 product only shows two detected strong aerosol layers (shown as purple boundaries) between $-25^{\circ}$ to $-30^{\circ}$ latitude, which is labeled as elevated smoke. These two aerosol layers should belong to a continuous one (shown in the red dashed box), but the VFM does not detect the faint aerosol (about $0.01 \mathrm{~km}^{-1}$ extinction) between the two strong aerosol layers (about $0.03 \mathrm{~km}^{-1}$ extinction). The attenuated scattering ratio (ASR) (Figure 3e) calculated from the CALIPSO Level 1 total attenuated backscatter and attenuated molecular backscatter product also demonstrates the overall continuous nature of this aerosol layer. 

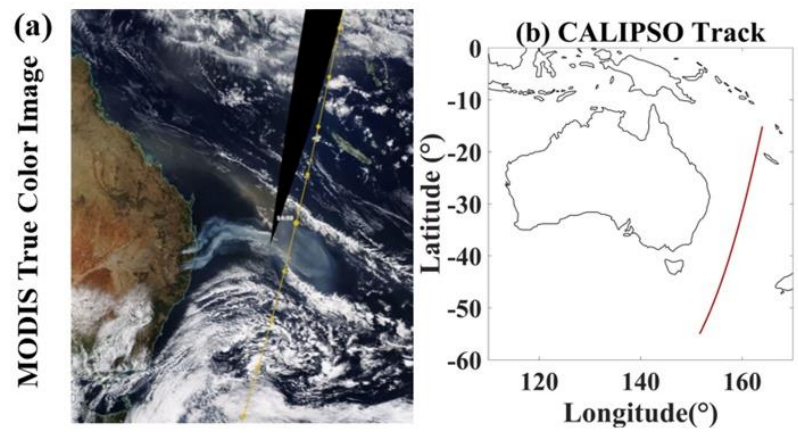

(d) 2019-09-08T14-22-29ZN-Aerosol Subtype

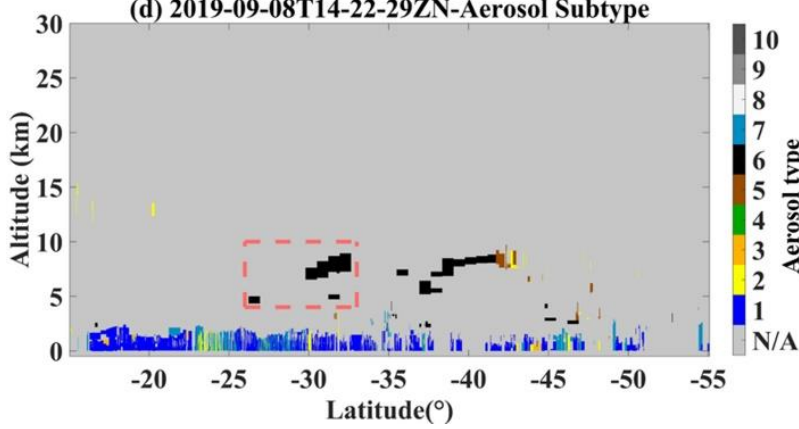

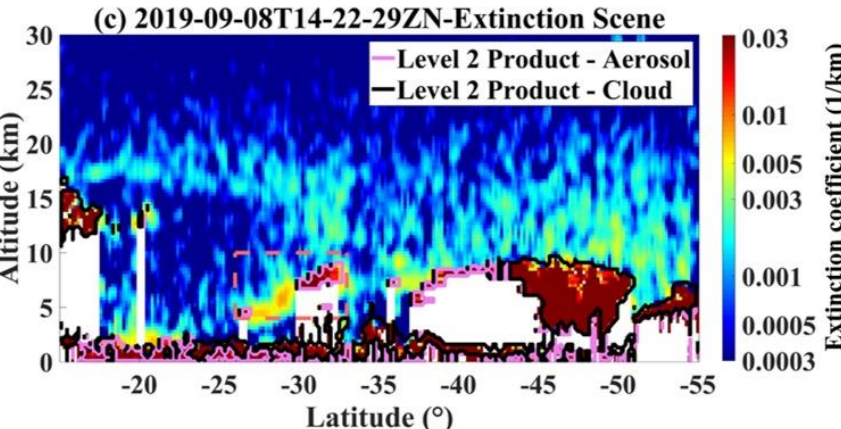

(e) 2019-09-08T14-22-29ZN-ASR Scene

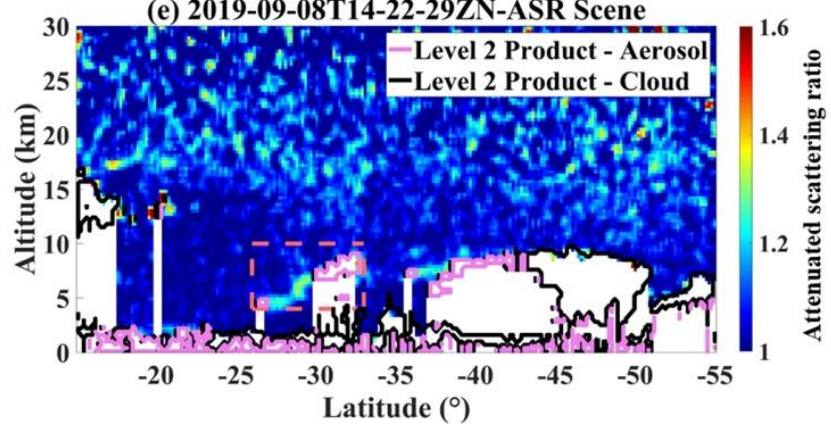

Figure 3. (a) MODIS Terra true-color image on daytime. (b) CALIPSO track of 2019-09-08T14-22-29ZN. (c) Latitude-altitude faint aerosol extinction of the corresponding nighttime CALIPSO track. The color represents the extinction coefficient $\left(\mathrm{km}^{-1}\right)$. The purple and black boundary lines and extinction inside represent the aerosol and cloud layers provided by CALIPSO Level 2 Aerosol and Cloud Profile products, respectively. The white areas represent the removed data below the layers. The retrieved faint aerosol at $20 \mathrm{~km}$ is shown after additional mean filtering $(3 \times 3$ window) to highlight the faint aerosol area. (d) Aerosol subty pes in CALIPSO VFM product $(\mathrm{N} / \mathrm{A}=$ not applicable, $1=$ marine, $2=$ dust, $3=$ polluted continental/smoke, $4=$ clean continental, $5=$ polluted dust, $6=$ elevated smoke, $7=$ dusty marine, $8=P S C$ aerosol, $9=$ =olcanic ash, 10=sulfate/other). (e) Attenuated scattering ratio.

\subsection{Comparison with SAGE III-ISS Product}

160 Figure 4 shows a case of the matched CALIPSO and SAGE III-ISS at latitude $33^{\circ}$ on August 26,2019 , as described in Section 2.3. An undetected faint aerosol layer (extinction coefficients around $0.005 \mathrm{~km}^{-1}$ ) is connected to the detected stratospheric aerosol layer provided by the CALIPSO product at altitudes of $15 \mathrm{~km}$ to $20 \mathrm{~km}$ around $20^{\circ}$ to $40^{\circ}$ latitude. Figure $4 \mathrm{~b}$ shows well the consistency of faint aerosol extinctions of CALIPSO and SAGE III-ISS (red dash line in Figure 4a) above $15 \mathrm{~km}$. 

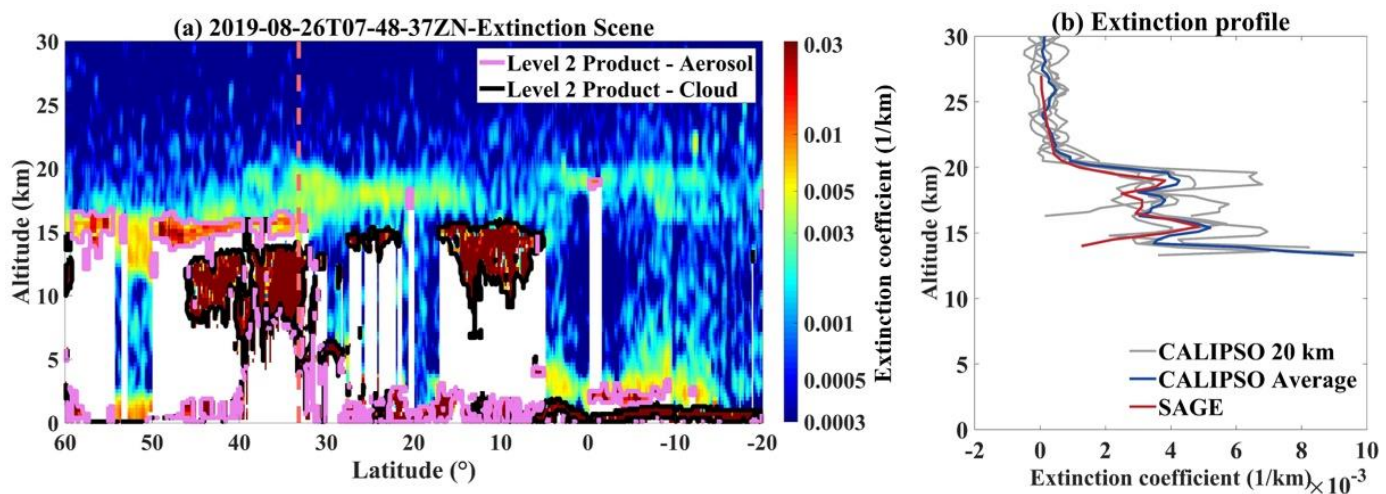

Figure 4. (a) Latitude-altitude faint aerosol extinction based on CALIPSO nighttime data on August 26, 2019, same as Figure 3c; (b) Comparison of faint aerosol extinction $\left(\mathrm{km}^{-1}\right)$ profile for matched CALIPSO and SAGE III-ISS observation. The gray lines represent the faint aerosol extinction of CALIPSO retrieval at a resolution of $20 \mathrm{~km}$ horizontally and $0.3 \mathrm{~km}$ vertically, and the blue line represents averaged gray lines. The red line represents the aerosol extinction from SAGE III-ISS.

170 The retrieved CALIPSO and SAGE III-ISS faint aerosol extinction from June 2017 to August 2019 shows good consistency, with correlation coefficient $(\mathrm{R})$ in logarithmic scale is 0.58 , and the root mean square error (RMSE) is 0.0008 , respectively (Figure 5a). The average (black line in Figure 5a) retrieved faint aerosol extinction from CALIPSO and SAGE III-ISS product is close to the 1:1 line, indicating low bias in the CALIPSO retrieval. Further, we can see that the retrieved aerosol extinction is much less than the detection limit $\left(0.01 \mathrm{~km}^{-1}\right)$ of the CALIPSO Level 2 product (Kacenelenbogen et al.,

175 2011; Toth et al., 2018;Winker et al., 2013). Likewise, Watson - Parris et al. (2018) noted through the model that the mean fraction of aerosol undetected by CALIOP daytime (nighttime) retrievals is $92 \%(87 \%)$ globally, with a minimum value of aerosol extinction close to $0.0001 \mathrm{~km}^{-1}$. The vast majority of un-retrieved aerosols were achieved in this study, which could complement the missing faint aerosol information in the CALIPSO products (Watson - Parris et al., 2018) and potentially be applied for validating reanalysis products.
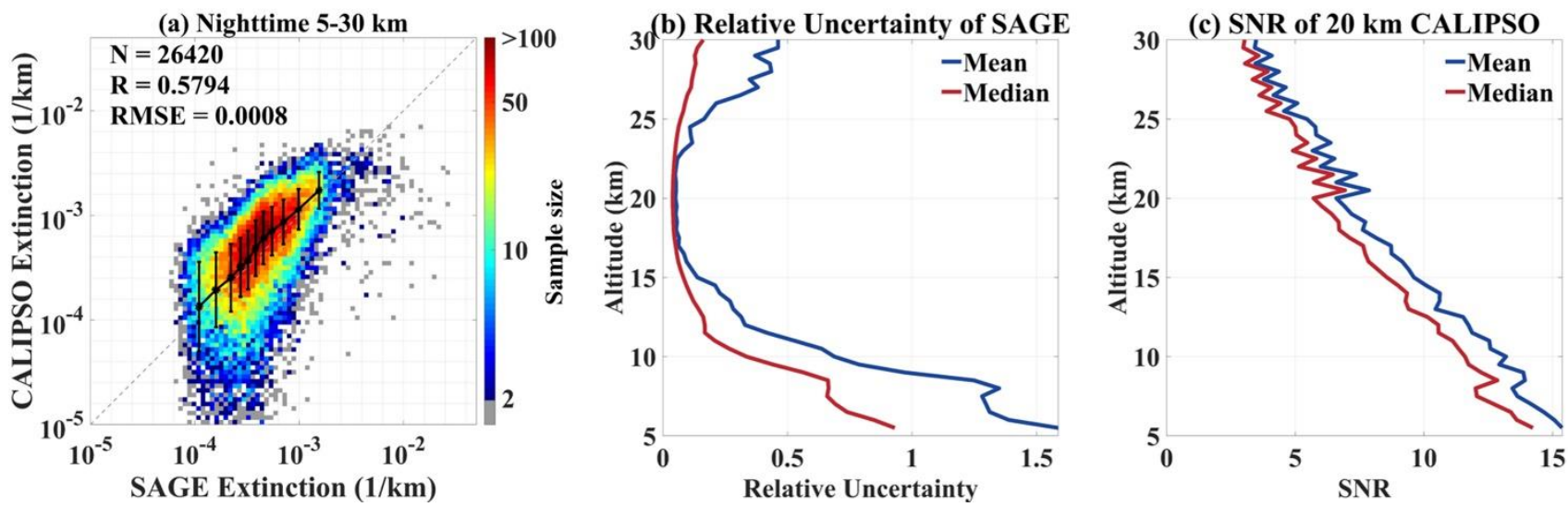

Figure 5. (a) Correlation plots of the retrieval within the matching grid of CALIPSO nighttime and SAGE III-ISS product from 5 $\mathrm{km}$ to $30 \mathrm{~km}$. (b) Vertical distribution of the mean and median of relative uncertainty in SAGE III-ISS product. (c) Vertical distribution of mean and median SNR of the TAB at $20 \mathrm{~km}$ horizontal resolution. The first and last bin (black dots in the middle of I-type bars) represent the mean values of $5 \%$ quantiles of SAGE III-ISS product and corresponding CALIPSO retrieval. The 

standard error of CALIPSO retrieval. Color represents the sample size. The root mean square error (RMSE) is calculated by $E=$ $\sqrt{\sum_{i=1}^{n}\left(\alpha_{i, \text { CALIPSO }}-\alpha_{i, S A G E}\right)^{2} / n}$.

Thomason et al. (2010) noted the prime observational region of SAGE III aerosol is in the stratosphere from 15 to $25 \mathrm{~km}$, while the errors for aerosol extinction products become large below $15 \mathrm{~km}$ (Figure 5b). We only use the SAGE data with relative uncertainty $\leq 10 \%$ for all altitude bins. The number of matched points below and above $15 \mathrm{~km}$ was filtered to 3297 and 23123, respectively. The comparison of CALIPSO retrieved aerosols extinction with SAGE III-ISS in Figure 5a is mainly in the stratosphere. Unlike SAGE III-ISS, CALIPSO has a higher SNR in the troposphere than in the stratosphere (Figure 5c). Therefore, the CALIPSO retrieval in the troposphere should be more reliable. Thus, we extend the retrieval into the troposphere considering, while the verification is un-performed due to the large uncertainty of SAGE III-ISS products in the troposphere.

The agreement between CALIPSO and SAGE III-ISS aerosol retrievals between 5 to $30 \mathrm{~km}$ during daytime (with R=0.16 and RMSE $=0.0034$ ) is worse than nighttime (with $\mathrm{R}=0.58$ and $\mathrm{RMSE}=0.0008$ ) (Figures 5a and 6a). The worse agreement is due to the lower SNR of CALIPSO during the daytime caused by sunlight (Figure 6b) (Hunt et al., 2009). Young et al. (2013) noted that the CALIPSO retrievals with $\mathrm{SNR} \leq 1$ usually contain a positive bias. The SNR during daytime above $20 \mathrm{~km}$ is usually less than 1 for TAB at $20 \mathrm{~km}$ horizontal scale (Figure 6b), which leads to a significantly positive bias in the retrieval, as shown in Figure 6a (Kim et al., 2017). The line of averaged extinction (black line in Figure 6a) does not pass through the center of the region of densest observations (red area in Figure 6a) due to negative values (not displayed with the logarithmic axes) from strong signal fluctuations during daytime. Additionally, the low SNR during daytime reduces the number of detected cloud and aerosol layers compared with nighttime (Huang et al., 2015), possibly leading to larger retrieved faint aerosol extinction.
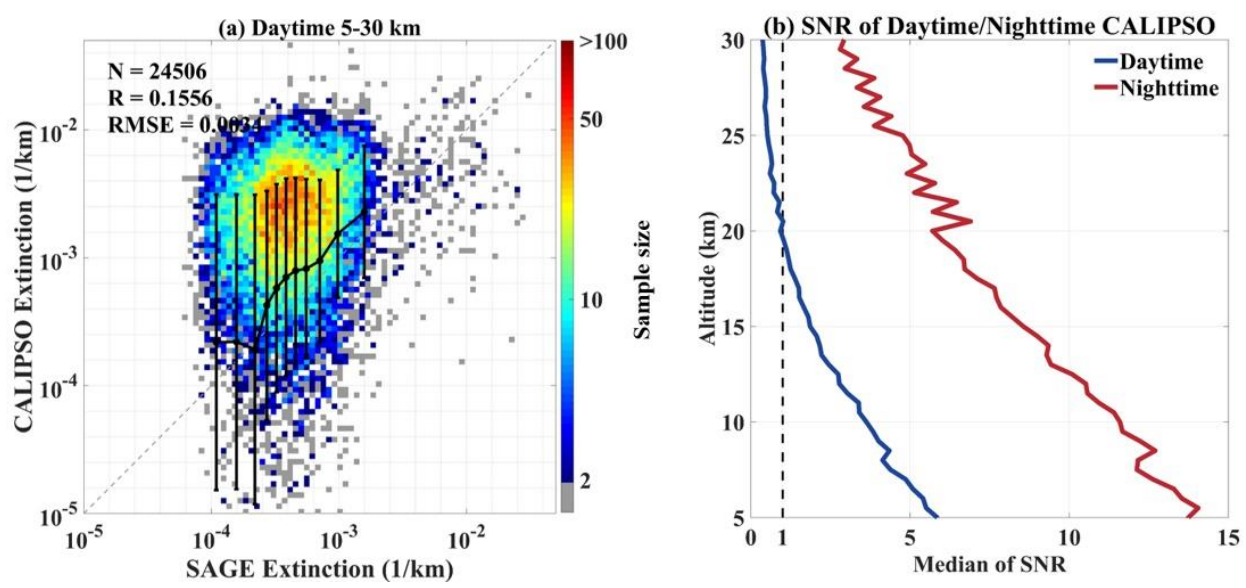

Figure 6. (a) Same as Figure 5a, but at daytime. (b) SNR profiles of the TAB at $20 \mathrm{~km}$ horizontal resolution at daytime (blue) and nighttime (red). 


\subsection{Comparison with CALIPSO Level 3 Stratospheric Aerosol Profile Product}

210 Figures 7a and 7b show the spatial distribution of aerosol extinction averaged on June and August at $15.2 \mathrm{~km}$ altitude from CALIPSO Level 3 monthly-averaged Stratospheric Aerosol Profile product with the resolution of $5^{\circ} \times 20^{\circ}$ in latitude and longitude (Kar et al., 2019). A significant amount of aerosol enhancement occurred in the stratosphere in August in the Northern Hemisphere (Figure 7b), possibly due to the onset of the Siberian fires in June of 2019 (Ohneiser et al., 2021;Kostrykin et al., 2021). We selected two CALIPSO tracks across Siberia at the initial and peak time of Siberia wildfires in June and August (Figure 7c and 7d), respectively. For the CALIPSO trajectory on June 10 at the beginning of wildfire, the stratosphere at northern hemisphere latitudes is clean, while natural dust aerosol prevails in the lower troposphere (Figure 7c and 7e). This detected clean condition by our retrieval is consistent with the result of Level 3 products, which indicate the clean stratosphere at a monthly temporal scale.
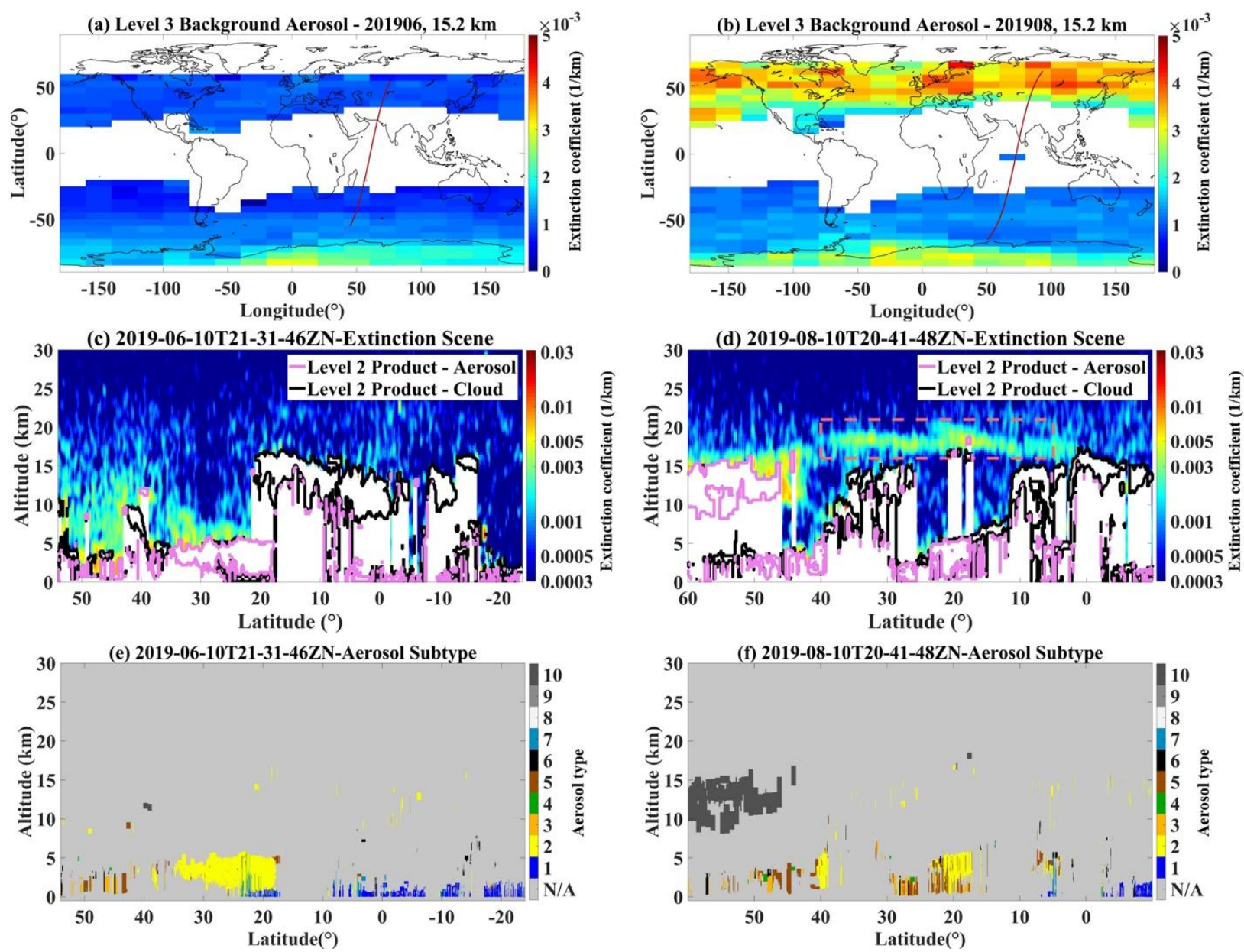

220 Figure 7. (a) and (b) are the stratospheric extinction distributions of CALIPSO Level 3 Stratospheric Aerosol Profile products at $15.2 \mathrm{~km}$ in June and August, respectively. (c) and (d) are the retrieved aerosol extinction scenes based on CALIPSO instantaneous data on June 10 and August 10, respectively, consistent with Figure 5a. The corresponding trajectories for the two scenes are shown as red lines in (a) and (b), and the corresponding aerosol subtypes are shown in (e) and (f), the same as Figure 5f. 
When the wildfires in Siberian become prevalent in August, there are strong aerosol layers classified as elevated smoke by VFM in the stratosphere between $50^{\circ} \mathrm{N}$ and $60^{\circ} \mathrm{N}$ in latitude (Figure $7 \mathrm{f}$ ). However, many faint aerosols are found and connected with the VFM aerosol layers (Figure $7 \mathrm{~d}$ ). These faint aerosols propagate from $60^{\circ} \mathrm{N}$ to near $10^{\circ} \mathrm{N}$ as shown in the red rectangle of Figure 7d, but are not indicated by the VFM. Figure 7b shows aerosol contamination in the entire northern hemisphere stratosphere at a monthly average scale. This propagation trajectory explains this same aerosol contamination based on instantaneous CALIPSO observation.

230 Therefore, the faint aerosol can be retrieved and detected by CALIPSO at $20 \mathrm{~km}$ horizontal resolution instantaneously compared to the current low temporal-spatial resolution Level 3 product. Aerosol significantly affects the Earth-atmosphere and precipitation by its direct and indirect effects (Dipu et al., 2013;Rosenfeld et al., 2014). However, it is constantly changing during its short lifetime and should be characterized and quantified at high temporal-spatial resolution. Instantaneous retrieval of faint aerosol at $20 \mathrm{~km}$ horizontal resolution provides a chance to deeper understand and quantify the aerosol impact on climate beyond the current CALIPSO Level 3 Stratospheric Aerosol Profile product.

\section{Conclusions}

An abundance of faint aerosols in the background atmosphere significantly affects the global climate (Chazette et al., 1995;Deshler, 2008). However, these faint aerosols are too optically thin to be instantaneously detected and retrieved by current methodologies (Watson - Parris et al., 2018;Toth et al., 2018). This study retrieved instantaneous faint aerosols based on CALIPSO Level 1B data, and compared them with the SAGE III-ISS products and CALIPSO Level 3 monthly average Stratospheric Aerosol Profile product. The main conclusions are summarized as follows:

(1) The retrieved faint aerosol extinction based on CALIPSO during nighttime shows good agreement with the SAGE IIIISS product with a correlation coefficient of 0.58 on a logarithmic scale and RMSE of 0.0008. The retrievable aerosol extinction greatly extends to $0.0001 \mathrm{~km}^{-1}$, much lower than the CALIPSO L2 product $\left(0.01 \mathrm{~km}^{-1}\right)$. The comparison is unavailable at low altitudes, but the retrieval should be more reliable (i.e., in the troposphere) because the SNR is higher.

(2) Due to sunlight during the daytime, the SNR of CALIPSO data is much lower (about 1/4 of nighttime), which leads to a positive bias of the retrieval with low R (0.16) and RMSE (0.0034) with SAGE III-ISS, respectively.

(3) CALIPSO Level 3 monthly products roughly indicate the enhanced stratospheric faint aerosol from the 2019 Siberian fires. Here, consistent faint aerosols are retrieved at a higher spatial resolution $(20 \mathrm{~km})$ and instantaneously. Further, our retrieval shows that these faint aerosols even propagate to near $10^{\circ} \mathrm{N}$, which is much beyond the detecting range of the CALIPSO L2 products $\left(50^{\circ} \mathrm{N}\right.$ and $\left.60^{\circ} \mathrm{N}\right)$.

This study allows more efficient capture of aerosol vertical properties of events, such as volcanic eruptions and wildfires, by acquiring instantaneous and high-resolution faint aerosols globally (Vernier et al., 2015;Andersson et al., 2015). Additionally, there is a large potential for new insights into the physical mechanism of aerosol-cloud interaction and quantifying the 
related radiative forcing more accurately (Boucher et al., 2013;Dipu et al., 2013). In this study, the lidar ratio was set at $50 \mathrm{sr}$ in the stratosphere and $28.75 \mathrm{sr}$ in the troposphere, which should be more carefully studied in the future (Kar et al., 2019; Khaykin et al., 2017; Sakai et al., 2016). Further, more attention should be focused on layer detection of tenuous aerosol and cloud layers and classification of aerosol subtypes, which will help improve the accuracy of faint aerosol retrievals.

Data availability: The datasets used in this study can be accessed from websites listed in Acknowledgements or by contacting the corresponding author.

Author contribution: D.R. and F.M. conceived the study. F.M., R.S. and Z.P. designed the retrieval methodology and comparison experiments. R.S. and Z.P implemented the methodology and carried out the data analysis. LZ, Y.Z. and X.L. contributed to the discussion of methodology and scientific significance. All co-authors commented on and reviewed the manuscript. RS prepared the manuscript with contributions from F.M. and the other co-authors.

Competing interests: The authors declare that they have no conflict of interest.

Acknowledgements: This study is supported by the National Natural Science Foundation of China (41971285 and 41627804) and the National Key Research and Development Program of China (2017YFC0212600). The numerical calculations in this paper have been done on the supercomputing system in the Supercomputing Center of Wuhan University. We thank the science teams for providing excellent and accessible data, including CALIPSO (https://asdc.larc.nasa.gov/project/CALIPSO) and SAGE III (https://sage.nasa.gov/missions/about-sage-iii-on-iss/).

\section{References}

Adams, A. M., Prospero, J. M., and Zhang, C.: CALIPSO-derived three-dimensional structure of aerosol over the Atlantic Basin and adjacent continents, Journal of Climate, 25, 6862-6879. doi:10.1175/JCLI-D-11-00672.1, 2012.

275 Adams, C., Bourassa, A., Bathgate, A., McLinden, C., Lloyd, N., Roth, C., Llewellyn, E., Zawodny, J., Flittner, D., and Manney, G.: Characterization of Odin-OSIRIS ozone profiles with the SAGE II dataset, Atmospheric Measurement Techniques, 6, 1447-1459. doi:10.5194/amt-6-1447-2013, 2013.

Andersson, S. M., Martinsson, B. G., Vernier, J.-P., Friberg, J., Brenninkmeijer, C. A., Hermann, M., Van Velthoven, P. F., and Zahn, A.: Significant radiative impact of volcanic aerosol in the lowermost stratosphere, Nature communications, 6, 1-8. doi:10.1038/ncomms8692, 2015 .

Boucher, O., Randall, D., Artaxo, P., Bretherton, C., Feingold, G., Forster, P., Kerminen, V.-M., Kondo, Y., Liao, H., and Lohmann, U.: Clouds and aerosols, in: Climate change 2013: the physical science basis. Contribution of Working Group I to the Fifth Assessment Report of the Intergovernmental Panel on Climate Change, Cambridge University Press, 571-657, 2013. 
Chazette, P., David, C., Lefrère, J., Godin, S., Pelon, J., and Mégie, G.: Comparative lidar study of the optical, geometrical, and dynamical properties of stratospheric post - volcanic aerosols, following the eruptions of El Chichon and Mount Pinatubo, Journal of Geophysical Research: Atmospheres, 100, 23195-23207. doi:10.1029/95JD02268, 1995.

Cisewski, M., Zawodny, J., Gasbarre, J., Eckman, R., Topiwala, N., Rodriguez-Alvarez, O., Cheek, D., and Hall, S.: The Stratospheric Aerosol and Gas Experiment (SAGE III) on the International Space Station (ISS) Mission, Sensors, Systems, and Next-Generation Satellites XVIII, 2014, 924107.

Damadeo, R. P., Zawodny, J. M., Thomason, L. W., and Iyer, N.: SAGE version 7.0 algorithm: application to SAGE II, Atmospheric Measurement Techniques, 6, 3539-3561. doi:10.5194/amt-6-3539-2013, 2013.

Deshler, T.: A review of global stratospheric aerosol: Measurements, importance, life cycle, and local stratospheric aerosol, Atmospheric Research, 90, 223-232. doi:10.1016/j.atmosres.2008.03.016, 2008.

Dipu, S., Prabha, T. V., Pandithurai, G., Dudhia, J., Pfister, G., Rajesh, K., and Goswami, B.: Impact of elevated aerosol layer on the cloud macrophysical properties prior to monsoon onset, Atmospheric Environment, 70, 454-467. doi:10.1016/j.atmosenv.2012.12.036, 2013.

Huang, J., Guo, J., Wang, F., Liu, Z., Jeong, M. J., Yu, H., and Zhang, Z.: CALIPSO inferred most probable heights of global dust and smoke layers, Journal of Geophysical Research: Atmospheres, 120, 5085-5100. doi:10.1002/2014JD022898, 2015.

Hunt, W. H., Winker, D. M., Vaughan, M. A., Powell, K. A., Lucker, P. L., and Weimer, C.: CALIPSO lidar description and performance assessment, Journal of Atmospheric and Oceanic Technology, 26, 1214-1228. doi:10.1175/2009JTECHA1223.1, 2009.

300 Kacenelenbogen, M., Vaughan, M., Redemann, J., Hoff, R., Rogers, R., Ferrare, R., Russell, P., Hostetler, C., Hair, J., and Holben, B.: An accuracy assessment of the CALIOP/CALIPSO version 2/version 3 daytime aerosol extinction product based on a detailed multi-sensor, multi-platform case study, Atmospheric Chemistry and Physics, 11, 3981-4000. doi:10.5194/acp-11-3981-2011, 2011.

Kar, J., Lee, K.-P., Vaughan, M. A., Tackett, J. L., Trepte, C. R., Winker, D. M., Lucker, P. L., and Getzewich, B. J.: CALIPSO level 3 stratospheric aerosol profile product: version 1.00 algorithm description and initial assessment, Atmospheric Measurement Techniques, 12 , 6173-6191. doi:10.5194/amt-12-6173-2019, 2019.

Khaykin, S. M., Godin-Beekmann, S., Keckhut, P., Hauchecorne, A., Jumelet, J., Vernier, J.-P., Bourassa, A., Degenstein, D. A., Rieger, L. A., and Bingen, C.: Variability and evolution of the midlatitude stratospheric aerosol budget from 22 years of ground-based lidar and satellite observations, Atmospheric Chemistry and Physics, 17, 1829-1845. doi:10.5194/acp-17-1829-2017, 2017.

Kim, M.-H., Yeo, H., Park, S., Park, D.-H., Omar, A., Nishizawa, T., Shimizu, A., and Kim, S.-W.: Assessing CALIOP-Derived Planetary

310 Boundary Layer Height Using Ground-Based Lidar, Remote Sensing, 13, 1496. doi:10.1002/2016JD025797, 2021.

Kim, M. H., Omar, A. H., Vaughan, M. A., Winker, D. M., Trepte, C. R., Hu, Y., Liu, Z., and Kim, S. W.: Quantifying the low bias of CALIPSO's column aerosol optical depth due to undetected aerosol layers, Journal of Geophysical Research: Atmospheres, 122, 10981113. doi:10.3390/rs13081496, 2017.

Kostrykin, S., Revokatova, A., Chernenkov, A., Ginzburg, V., Polumieva, P., and Zelenova, M.: Black Carbon Emissions from the

315 Siberian Fires 2019: Modelling of the Atmospheric Transport and Possible Impact on the Radiation Balance in the Arctic Region, Atmosphere, 12, 814. doi:10.3390/atmos12070814, 2021.

Kremser, S., Thomason, L. W., von Hobe, M., Hermann, M., Deshler, T., Timmreck, C., Toohey, M., Stenke, A., Schwarz, J. P., and Weigel, R.: Stratospheric aerosol-Observations, processes, and impact on climate, Reviews of Geophysics, 54, 278-335. doi:10.1002/2015RG000511, 2016.

320 Lee, L. A., Reddington, C. L., and Carslaw, K. S.: On the relationship between aerosol model uncertainty and radiative forcing uncertainty, Proceedings of the National Academy of Sciences, 113, 5820-5827. doi:10.1073/pnas.1507050113, 2016. 
Levy, R., Mattoo, S., Munchak, L., Remer, L., Sayer, A., Patadia, F., and Hsu, N.: The Collection 6 MODIS aerosol products over land and ocean, Atmospheric Measurement Techniques, 6, 2989-3034. doi:10.5194/amt-6-2989-2013, 2013.

Li, Z., Guo, J., Ding, A., Liao, H., Liu, J., Sun, Y., Wang, T., Xue, H., Zhang, H., and Zhu, B.: Aerosol and boundary-layer interactions and impact on air quality, National Science Review, 4, 810-833. doi:10.1093/nsr/nwx117, 2017.

Liu, Z., Kar, J., Zeng, S., Tackett, J., Vaughan, M., Avery, M., Pelon, J., Getzewich, B., Lee, K.-P., Magill, B., Omar, A., Lucker, P., Trepte, C., and Winker, D.: Discriminating between clouds and aerosols in the CALIOP version 4.1 data products, Atmospheric Measurement Techniques, 12, 703-734. doi:10.5194/amt-12-703-2019, 2019.

Lu, X., Mao, F., Pan, Z., Gong, W., Wang, W., Tian, L., and Fang, S.: Three-dimensional physical and optical characteristics of aerosols over central china from long-term calipso and hysplit data, Remote Sensing, 10, 314. doi:10.3390/rs10020314, 2018.

Ma, P. L., Rasch, P. J., Wang, M., Wang, H., Ghan, S. J., Easter, R. C., Gustafson Jr, W. I., Liu, X., Zhang, Y., and Ma, H. Y.: How does increasing horizontal resolution in a global climate model improve the simulation of aerosol - cloud interactions?, Geophysical Research Letters, 42, 5058-5065. doi:10.1002/2015GL064183, 2015.

Mauldin III, L., Zaun, N., McCormick Jr, M., Guy, J., and Vaughn, W.: Stratospheric Aerosol and Gas Experiment II instrument: A functional description, Optical Engineering, 24, 242307. doi:10.1117/12.7973473, 1985.

Ohneiser, K., Ansmann, A., Chudnovsky, A., Engelmann, R., Ritter, C., Veselovskii, I., Baars, H., Gebauer, H., Griesche, H., and Radenz, M.: The unexpected smoke layer in the High Arctic winter stratosphere during MOSAiC 2019-2020, Atmospheric Chemistry and Physics, 21, 15783-15808. doi:10.5194/acp-21-15783-2021, 2021.

Rosenfeld, D., Andreae, M. O., Asmi, A., Chin, M., de Leeuw, G., Donovan, D. P., Kahn, R., Kinne, S., Kivekäs, N., and Kulmala, M.:

340 Global observations of aerosol-cloud-precipitation-climate interactions, Reviews of Geophysics, 52, $750-808$. doi:10.1002/2013RG000441, 2014.

Sakai, T., Uchino, O., Nagai, T., Liley, B., Morino, I., and Fujimoto, T.: Long - term variation of stratospheric aerosols observed with lidars over Tsukuba, Japan, from 1982 and Lauder, New Zealand, from 1992 to 2015, Journal of Geophysical Research: Atmospheres, 121, 10,283-210,293. doi:10.1002/2016JD025132, 2016.

345 Schwartz, S. E., and Andreae, M. O.: Uncertainty in climate change caused by aerosols, Science, 272, $1121-1121$. doi:10.1126/science.272.5265.1121, 1996.

Smirnov, A., Holben, B., Giles, D., Slutsker, I., O'Neill, N., Eck, T., Macke, A., Croot, P., Courcoux, Y., and Sakerin, S.: Maritime aerosol network as a component of AERONET-first results and comparison with global aerosol models and satellite retrievals, Atmospheric Measurement Techniques, 4, 583-597. doi:10.5194/amt-4-583-2011, 2011.

350 Song, Q., Zhang, Z., Yu, H., Ginoux, P., and Shen, J.: Global dust optical depth climatology derived from CALIOP and MODIS aerosol retrievals on decadal timescales: regional and interannual variability, Atmospheric Chemistry and Physics, 21, 13369-13395. doi:10.5194/acp-21-13369-2021, 2021.

Thomason, L., Moore, J., Pitts, M., Zawodny, J., and Chiou, E.: An evaluation of the SAGE III version 4 aerosol extinction coefficient and water vapor data products, Atmospheric Chemistry and Physics, 10, 2159-2173. doi:10.5194/acp-10-2159-2010, 2010.

355 Thomason, L. W., Pitts, M. C., and Winker, D. M.: CALIPSO observations of stratospheric aerosols: a preliminary assessment, Atmospheric Chemistry and Physics, 7, 5283-5290. doi:10.5194/acp-7-5283-2007, 2007.

Thorsen, T. J., and Fu, Q.: CALIPSO - inferred aerosol direct radiative effects: Bias estimates using ground - based Raman lidars, Journal of Geophysical Research: Atmospheres, 120, 12,209-212,220. doi:10.1002/2015JD024095, 2015. 
https://doi.org/10.5194/acp-2022-56

Preprint. Discussion started: 16 February 2022

(c) Author(s) 2022. CC BY 4.0 License.

(c) (i)

Atmospheric

Chemistry

and Physics

Discussions

Toth, T. D., Campbell, J. R., Reid, J. S., Tackett, J. L., Vaughan, M. A., Zhang, J., and Marquis, J. W.: Minimum aerosol layer detection sensitivities and their subsequent impacts on aerosol optical thickness retrievals in CALIPSO level 2 data products, Atmospheric Measurement Techniques, 11, 499-514. doi:10.5194/amt-11-499-2018, 2018.

Turco, R., Whitten, R., Toon, O., Pollack, J., and Hamill, P.: OCS, stratospheric aerosols and climate, Nature, 283, $283-285$. doi:10.1038/283283a0, 1980 .

Vernier, J.-P., Pommereau, J.-P., Garnier, A., Pelon, J., Larsen, N., Nielsen, J., Christensen, T., Cairo, F., Thomason, L. W., and Leblanc,

365 T.: Tropical stratospheric aerosol layer from CALIPSO lidar observations, Journal of Geophysical Research: Atmospheres, 114. doi:10.1029/2009JD011946, 2009.

Vernier, J. P., Fairlie, T., Natarajan, M., Wienhold, F., Bian, J., Martinsson, B., Crumeyrolle, S., Thomason, L., and Bedka, K.: Increase in upper tropospheric and lower stratospheric aerosol levels and its potential connection with Asian pollution, Journal of Geophysical Research: Atmospheres, 120, 1608-1619. doi:10.1002/2014JD022372, 2015.

370 Watson - Parris, D., Schutgens, N., Winker, D., Burton, S. P., Ferrare, R. A., and Stier, P.: On the limits of CALIOP for constraining modeled free tropospheric aerosol, Geophysical Research Letters, 45, 9260-9266. doi:10.1029/2018GL078195, 2018.

Watson - Parris, D., Bellouin, N., Deaconu, L., Schutgens, N. A., Yoshioka, M., Regayre, L. A., Pringle, K. J., Johnson, J. S., Smith, C., and Carslaw, K.: Constraining uncertainty in aerosol direct forcing, Geophysical Research Letters, 47, e2020GL087141. doi:10.1029/2020GL087141, 2020.

375 Winker, D., Pelon, J., Coakley Jr, J., Ackerman, S., Charlson, R., Colarco, P., Flamant, P., Fu, Q., Hoff, R., and Kittaka, C.: The CALIPSO mission: A global 3D view of aerosols and clouds, Bulletin of the American Meteorological Society, 91, 1211-1230. doi:10.1175/2010BAMS3009.1, 2010.

Winker, D., Tackett, J., Getzewich, B., Liu, Z., Vaughan, M., and Rogers, R.: The global 3-D distribution of tropospheric aerosols as characterized by CALIOP, Atmospheric Chemistry and Physics, 13, 3345-3361. doi:10.5194/acp-13-3345-2013, 2013.

380 Young, S. A., Vaughan, M. A., Kuehn, R. E., and Winker, D. M.: The retrieval of profiles of particulate extinction from Cloud-Aerosol Lidar and Infrared Pathfinder Satellite Observations (CALIPSO) data: Uncertainty and error sensitivity analyses, Journal of Atmospheric and Oceanic Technology, 30, 395-428. doi:10.1175/JTECH-D-12-00046.1, 2013.

Young, S. A., Vaughan, M. A., Garnier, A., Tackett, J. L., Lambeth, J. D., and Powell, K. A.: Extinction and optical depth retrievals for CALIPSO's Version 4 data release, Atmospheric Measurement Techniques, 11, 5701-5727. doi:10.5194/amt-11-5701-2018, 2018. 